\title{
Lessons Learned on the Tensile and Bond Behavior of Fabric Reinforced Cementitious Matrix (FRCM) Composites
}

\author{
Gianmarco de Felice ${ }^{1,2 *}$, Tommaso $D^{\prime}$ Antino $^{3}$, Stefano De Santis ${ }^{1}$, Pietro Meriggi ${ }^{1}$ and \\ Francesca Roscini ${ }^{1}$
}

${ }^{1}$ Department of Engineering, Roma Tre University, Rome, Italy, ${ }^{2}$ Italian Academy for Advanced Studies in America, Columbia University, New York, NY, United States, ${ }^{3}$ Politecnico di Milano, Department of Architecture, Built environment and Construction engineering, Milan, Italy

OPEN ACCESS

Edited by:

Giovanni Minafò,

University of Palermo, Italy

Reviewed by:

Michela Lerna,

Politecnico di Bari, Italy

Francesca Nerilli,

University Niccolò Cusano, Italy

*Correspondence:

Gianmarco de Felice

gianmarco.defelice@uniroma3.it

Specialty section

This article was submitted to

Earthquake Engineering,

a section of the journal

Frontiers in Built Environment

Received: 15 November 2019

Accepted: 13 January 2020

Published: 07 February 2020

Citation:

de Felice G, D'Antino T, De Santis S,

Meriggi $P$ and Roscini $F$ (2020)

Lessons Learned on the Tensile and

Bond Behavior of Fabric Reinforced

Cementitious Matrix (FRCM)

Composites. Front. Built Environ. 6:5

doi: 10.3389/fbuil.2020.00005
Fabric Reinforced Cementitious Matrix (FRCM) composites represent an effective, compatible, and cost-efficient solution for strengthening and retrofitting existing structures. A strong research effort was done to investigate the tensile and bond properties of these materials, as well as the overall behavior of strengthened members. A Round Robin Test was organized by Rilem TC 250-CSM on 28 FRCM composites comprising basalt, carbon, glass, $\mathrm{PBO}$, aramid and steel textiles, embedded in either cement, lime or geopolymer mortars, to collect an experimental dataset and define test protocols. This paper collects the outcomes of this study to highlight fundamental properties of FRCM and to investigate the variability of test results. Grid spacing, equivalent thickness of the textiles and mechanical properties of FRCM composites, such as stiffness, tensile and bond strength, are provided. Based on the comparison of experimental outcomes, the scatter of the mechanical properties is estimated, as a consequence of the quasi-brittle behavior of the inorganic matrix and its sensitivity to manufacturing, curing and handling processes. Eventually, the influence of testing implementation, such as gripping method and measuring techniques, is outlined.

Keywords: retrofitting, round robin test (RRT), steel reinforced grout (SRG), strengthening, shear bond tests, textile reinforced mortar (TRM), tensile tests

\section{INTRODUCTION}

Externally bonded (EB) reinforcements with inorganic-matrix composites are a particularly effective solution for repairing and strengthening existing concrete and masonry structures. They comprise high performance textiles made of aramid, basalt (Balsamo et al., 2011; Papanicolaou et al., 2011; Marcari et al., 2017), carbon (D’Ambrisi et al., 2013; Babaeidarabad et al., 2014; Pino et al., 2017), glass (Carozzi and Poggi, 2015; Raoof et al., 2017; Cascardi et al., 2018; Castellano et al., 2019, D'Antino et al., 2019), PBO (polyparaphenylene benzobisoxazole) (D'Ambrisi and Focacci, 2011; Alecci et al., 2016; D’Antino et al., 2018a), or natural (Codispoti et al., 2015) long fibers, usually arranged in bidirectional open meshes. Alternatively, steel cords or ropes can be used, which are assembled parallel to each other to form unidirectional textiles (Borri et al., 2009; Napoli and Realfonzo, 2015; De Santis, 2017; Bellini et al., 2018; Ombres and Verre, 2019). Textiles are bonded to the structural elements by lime, cement, or geopolymer mortars with the thickness 
typical of a plaster layer. Inorganic-matrix composites are usually referred to as Fabric Reinforced Cementitious Matrix (FRCM) or Textile Reinforced Mortar (TRM), whereas the term Steel Reinforced Grout (SRG) is generally adopted for those comprising steel textiles.

Thanks to their high strength-to-weight ratio, FRCM systems can significantly improve the structural capacity with minimum encumbrance and mass increase, and accordingly are particularly suitable for seismic retrofitting (Papanicolaou et al., 2007, 2011; De Santis et al., 2018b, 2019a,b). At the same time, the use of an inorganic matrix makes them easy to install even on irregular or wet surfaces and provides good behavior under high temperatures. Lime-based mortars also ensure physical/chemical compatibility with masonry substrates, vapor permeability, and reversibility, complying with the principles of conservation of architectural heritage. For all these reasons, FRCM systems are now considered competitive, or even preferable in some cases, over Fiber Reinforced Polymers (FRP), which employ epoxy or polyester resins, even if organic binders may provide a higher substrate-to-composite bond capacity than mortars.

Driven by such potentialities, significant research achievements, and technological advancements have been gained in the last decade, in response to the need of innovative technologies for improving the safety level of the building stock, whose aging is increasing the costs for its maintenance and repair. The knowledge gained so far led to the development of product qualification and retrofitting design guidelines, overcoming two main obstacles to the confident use of FRCM composites in rehabilitation practice (Figure 1). Indeed, recent industrial developments made a number of systems available in the market. Some of them have already been applied in the field, especially in earthquakes prone areas and on masonry structures (Valluzzi et al., 2014). On the other hand, a deeper understating still needs to be developed on the durability of FRCM systems, which is a key element for ensuring its sustainability in terms of long-term effectiveness and environmental impact (energy used for production, disposal of waste materials).

The investigations carried out so far on the mechanical behavior of FRCM composites and on the response of FRCMstrengthened structures highlighted their complex behavior, which is related to the brittle nature of the mortar matrix and to the matrix-fiber interaction (de Felice et al., 2014; Sneed et al., 2014; Carloni et al., 2018). Manufacturing and curing conditions, installation details, and small geometric variations may strongly affect crack development and ultimate strength. Furthermore, the bond between FRCM and the substrate strongly depends on the strength and roughness of the substrate, the mechanical properties of the matrix, and textile layout (grid spacing, presence of coating of pre-impregnation, stitching between warp and weft bundles), resulting in different failure modes: not only cohesive debonding within the substrate, as it happens in FRP systems, but also detachment at the reinforcement-to-substrate interface or between the textile and the matrix, or textile slippage within the matrix.

Acceptance procedures are based either on clevis-gripped tensile tests or on the combination of clamping-gripped tensile and bond tests (De Santis et al., 2018a). Accordingly, recent studies have been devoted to the development of standardized methods for direct tensile and shear bond tests (De Santis et al., 2017a; D'Antino et al., 2018b), resulting in a RILEM recommendation (de Felice et al., 2018). Nevertheless, the crucial issues of the reliability and repeatability of test results have not been deeply tackled yet, because of the lack of wide experimental and consistent datasets. To this purpose, a Round Robin Test (RRT) was organized by the Rilem TC 250-CSM (Composites for the Sustainable Strengthening of Masonry) and Assocompositi (Italian Industry Association for Composite Materials). The RRT involved 19 European research institutions and 11 industrial partners. A total of 28 FRCM composites were investigated, comprising aramid, basalt, carbon, glass, $\mathrm{PBO}$, and steel textiles,

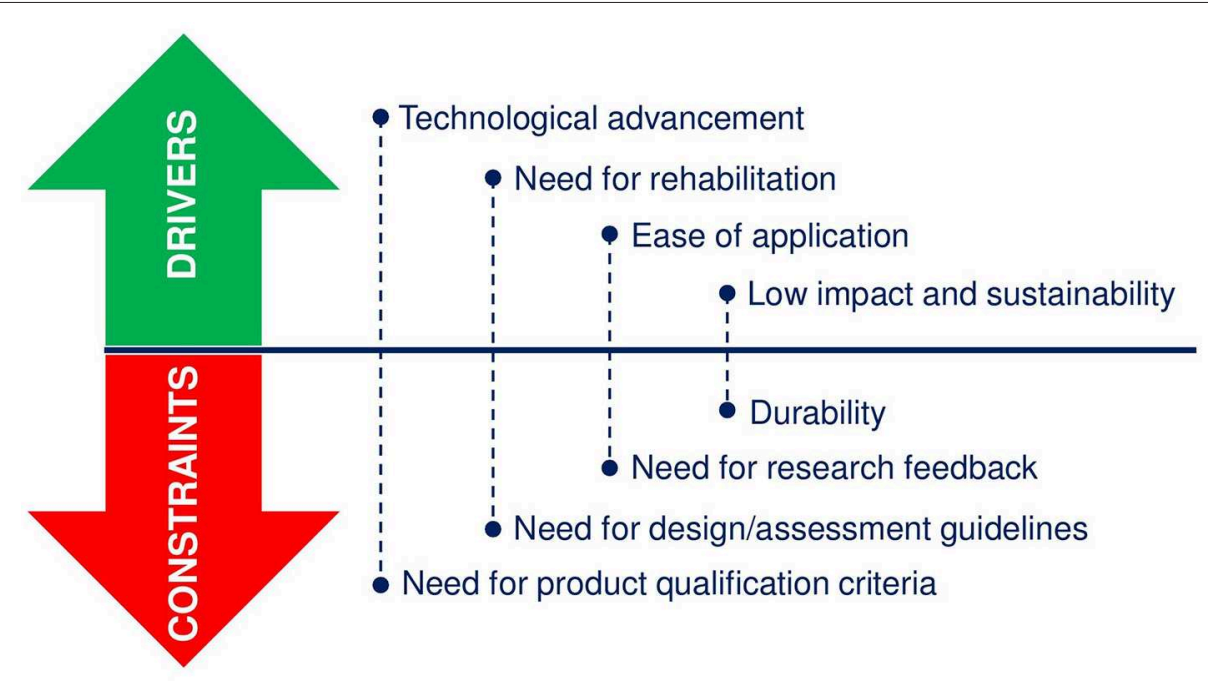

FIGURE 1 | Key drivers and constraints for FRCM development and application. 
embedded into lime, cement, and geopolymer mortars. Direct tensile tests were carried out to derive stiffness, crack pattern, and tensile strength. Shear bond tests provided composite-tosubstrate load transfer capacity and failure mode. Test results are presented in detail in five papers organized by textile material, namely: basalt (Lignola et al., 2017), carbon (Carozzi et al., 2017), glass (Leone et al., 2017), aramid and PBO (Caggegi et al., 2017), and steel (De Santis et al., 2017b).

In this work, the results obtained during the RRT initiative are analyzed to identify the fundamental properties needed for a complete mechanical characterization of FRCM composite. The repeatability of experimental tests is also analyzed and the confidence associated to the mechanical properties determined from the tests is discussed.

\section{OVERVIEW OF THE ROUND ROBIN TEST}

\section{Institutions Involved}

Rilem TC 250-CSM (Composites for the Sustainable Strengthening of Masonry) and Assocompositi (Italian Industry Association for Composite Materials) organized a Round Robin
Test (RRT) for the characterization of various FRCM composites. This initiative was aimed at (i) form a large experimental database including information on numerous FRCM composites, (ii) providing advancement on the knowledge of FRCM mechanical behavior, (iii) analyse the repeatability/variability associated with tensile and bond tests, together with the causes of variability, and (iv) developing standardized procedures for the mechanical characterization of these materials.

Nineteen research institutions were involved, from 7 European Countries (France, Germany, Greece, Italy, Poland, Portugal and Slovenia). A total of 28 systems were investigated, supplied by 11 industrial partners (ten Italian and one Greek), as listed in Table 1 (details on the properties of each system are provided in the following section). Two systems (namely G9 and G10) comprised a glass FRP mesh, which means that they are not strictly FRCM system but Composite Reinforced Mortar (CRM) systems.

The same system was tested by at least two institutions (although results on aramid systems were available only from one institution), which allowed for comparing the results and analyzing the effect of the experimental setups and testing

TABLE 1 | Overview of the round robin test.

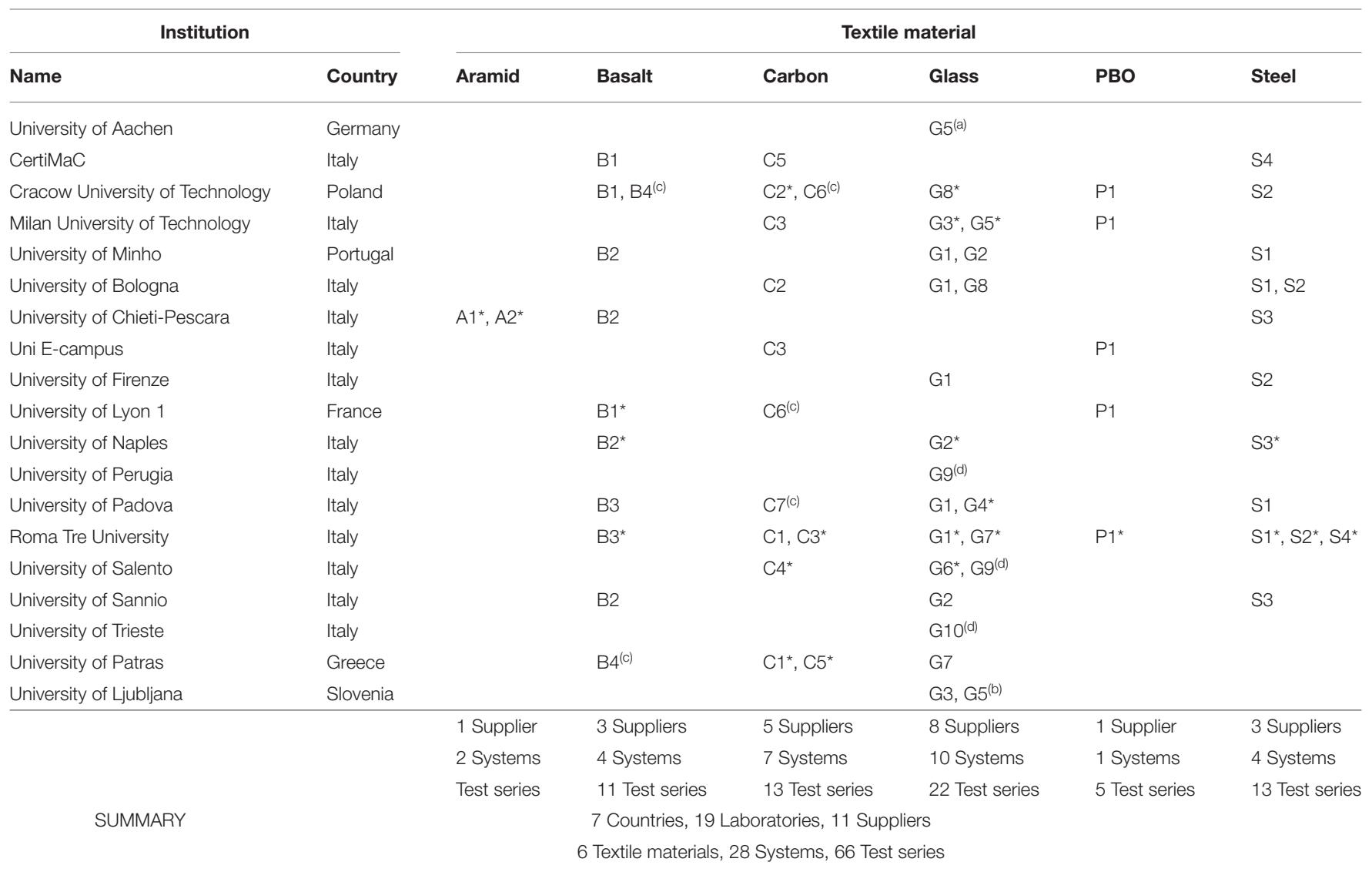

\footnotetext{
(a) Only direct tensile tests.

(b) Only shear bond tests. This institution is the only one that used a double-lap setup for shear bond tests.

(c) Test results unreliable for this system. Excluded from the statistics in this paper.

(d) Composite Reinforced Mortar systems. Excluded from the statistics in this paper.

${ }^{*}$ Results included in the statistics presented and discussed in this paper.
} 
procedure. The RRT included 66 test series, each comprising five direct tensile tests and five shear bond tests (except for two series including glass FRCM systems).

After the execution of experimental tests, the results were shared, discussed, and compared amongst the involved institutions. This analysis led to the improvement of knowledge not only on the mechanical behavior of FRCM systems but also on test methodologies. Some features of specimen preparation (manufacturing, curing, wrapping of coupon edges) and of experimental setups (gripping methods, measurement devices, alignment) were considered unsuitable and the corresponding results unreliable. On this basis, as one of the main contributions of the RRT, test methods were proposed (De Santis et al., 2017a) and test recommendations for FRCM-to-substrate bond characterization were developed (de Felice et al., 2018).

Table 1 collects all the systems and test series of the RRT. The results assumed as reliable and included in the statistics of this paper are identified by an asterisk, for a total of 23 FRCM systems. On the other hand, results whose reliability was considered questionable by RRT participants and results on CRM systems were excluded.

\section{Experimental Tests Performed}

Five direct tensile tests and five shear bond tests were carried out on each FRCM system considered by the specific institution. Direct tensile tests provided the constitutive relationship of FRCM composites, which is generally characterized by three response stages. In the first stage, the applied load is mainly borne by the uncracked matrix; in the second stage, progressive matrix cracking occurs, and the applied load is transferred from the matrix to the embedded fibers; in the third stage, the matrix is fully cracked (no new cracks appear) and the applied load is mainly sustained by the textile. Therefore, the specimen stiffness during the third stage and the FRCM tensile strength are mainly associated with textile properties, even if the matrix is still responsible for a certain load redistribution and tension stiffening effect. Tensile tests were carried out under displacement control on prismatic specimens (coupons). The load was measured by a load cell and the axial stress was conventionally calculated referring to the cross sectional area of the dry textile. Axial strains were recorded using displacement transducers or extensometers directly applied to the specimen, or also by means of non-contact optical methods (De Santis, 2017; Tekieli et al., 2017; Caggegi et al., 2018).

Shear bond tests provided the maximum stress, referred to as bond capacity, which can be transferred from the structural element to the externally bonded reinforcement. This stress can be used to compute the maximum load that can be borne by the EB FRCM, unless pins or anchors are applied to prevent (or delay) debonding or unless the tensile rupture of the textile takes place. Shear bond tests were carried out with universal testing machines or with movable actuators and various stiff steel frames were employed to ensure the correct alignment of the specimen. The load was recorded by a load cell and divided by the dry fabric cross-sectional area to obtain the axial stress in the textile. The relative displacement between the substrate and the textile at the EB composite strip loaded end (named slip) was computed as the average of the measurements of two displacement transducers attached to the substrate at the side of the strip. In some cases, non-contact optical methods were also adopted to measure the textile slip.

In order to minimize the result variability and allow for comparisons, general instructions for direct tensile tests and shear bond tests regarding specimen manufacturing (geometry, curing), test execution (experimental setup, displacement rate) and experimental outcomes to be collected (main output data, graphs) were provided. However, details of specimen geometry, particular curing conditions, specific setup, and instrumentation slightly varied from laboratory to laboratory. As a result, for direct tensile tests (Figure 2A) the thickness of the specimens was $10 \mathrm{~mm}$, whilst the width ranged from 40 to $100 \mathrm{~mm}$ depending on the textile layout (the width was recommended to be a multiple of the yarn spacing) and on the testing setup. Each laboratory could select the specimen gripping and strain measuring methods. The stress-strain response curve had to be provided, along with key parameters (peak stress and corresponding strain, slope of the curves during specific stages, etc.), the crack pattern, and the failure mode observed. The substrates used for shear bond tests (Figure 2B) were masonry prisms made by five $55 \mathrm{~mm}$ thick clay bricks, supplied by San Marco Terreal, Italy, under the name San Marco Rosso Vivo A6R55W. The mechanical properties of the bricks are $14.8 \mathrm{~N} / \mathrm{mm}^{2}$ compressive strength, $2.5 \mathrm{~N} / \mathrm{mm}^{2}$ tensile strength and $5.76 \mathrm{kN} / \mathrm{mm}^{2}$ Young's modulus (determined experimentally). Depending on the geometry (width) of the FRCM strip to be bonded to the substrate and on laboratory facilities, some prisms were constructed with whole bricks, whereas others with half bricks. Lime mortar with compressive strength of M5 strength class was recommended for the four mortar bed joints (the actual compressive strength of the mortar varied from participant to participant). In the RRT, the same substrate material was chosen for all the tests, to reduce the number of parameters investigated, but the load FRCM-tosubstrate load transfer capacity could rely on the properties of the substrate. Indeed, Italian certification guidelines require bond tests on different (although standardized) substrate materials. The bonded length was $260 \mathrm{~mm}$ for all tests and started $30 \mathrm{~mm}$ apart from the edge of the prism at the loaded end. The bonded width was kept equal to that of the coupons used in direct tensile tests. Also in the case of shear bond tests, the laboratories chose the setup type (18 institutions used a single lap configuration, whereas one used a double lap configuration), the bare textile gripping method, and the method to measure the slip. The outcomes of these tests were the axial stress-slip responses, along with the peak axial stress, the corresponding slip, and the failure mode observed. To facilitate result comparisons, the failure modes were classified as: debonding with cohesive failure of the substrate (A), debonding at the matrix-to-substrate (B) or at the textile-to-matrix $(C)$ interface, textile slippage within the matrix (D), and tensile rupture of the textile inside or outside the bonded area (E) (de Felice et al., 2018).

\section{Systems Under Investigation}

The 23 FRCM systems included in the analysis of this paper comprised 22 different textiles, 2 of which were made of aramid, 


\section{A}

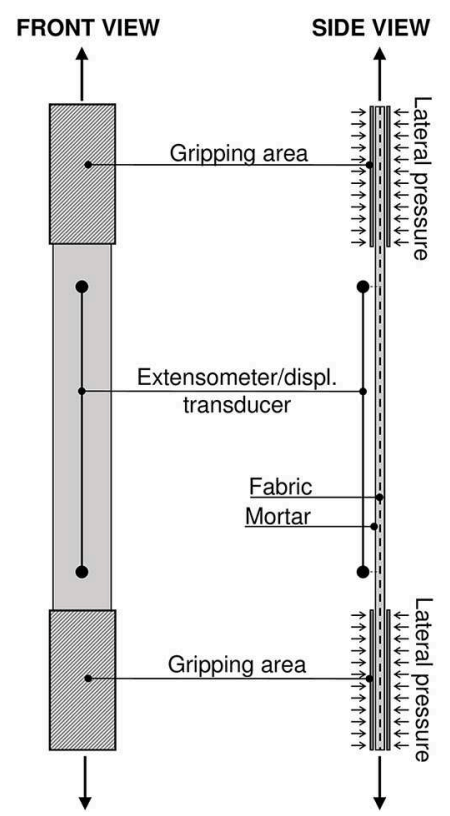

B

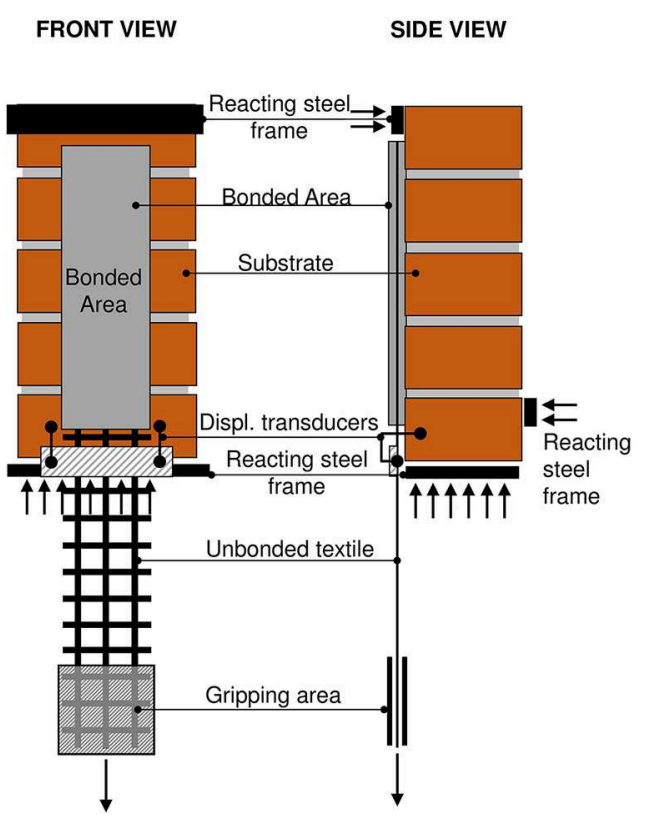

FIGURE 2 | Direct tensile tests on FRCM composite specimen (A) and shear bond tests on masonry substrate (B).

3 of basalt, 5 of carbon, 8 of glass, 1 of $\mathrm{PBO}$, and 3 of steel (Table 2). Beside the type of fiber, the textiles differed by layout (dimensions and shape of the yarns, yarn spacing, and direction), presence of yarn coating or impregnation and weaving technique. Each of these parameters affect the matrix-fiber interaction and led to a specific behavior of the FRCM system. All steel textiles and one aramid textile were unidirectional; the other aramid fabric was quadriaxial. All the other fabrics were bidirectional, 15 with the same surface mass density in each direction (i.e., balanced textiles) and 2 with a higher surface mass density in the warp direction (i.e., unbalanced textiles). The steel textiles were made by steel cords comprising single wires, each with diameter lower than $1 \mathrm{~mm}$, twisted together to provide stability to the textile and improve the matrix-fiber interlocking. For some textiles, single bundles (yarns) were coated, or fully impregnated with resin to improve the matrixfiber bond properties and improve the fiber durability. When uncoated, glass textiles where made by alkali-resistant (AR) glass fibers to prevent fiber degradation in alkaline environment, such as the mortar paste. In order to improve the interlock with matrix, longitudinal (warp), and transversal (weft) yarns of some bidirectional textiles were firmly connected together using stitches (D'Antino and Papanicolaou, 2017). Excluding steel textiles, the grid spacing (i) ranged from $6 \times 6 \mathrm{~mm}$ (a basalt mesh) to $30 \times 30 \mathrm{~mm}$ (a carbon mesh), the surface mass density $(\gamma)$ from $44 \mathrm{~g} / \mathrm{m}^{2}$ (PBO) to $360 \mathrm{~g} / \mathrm{m}^{2}$ (glass) and the equivalent thickness ( $\mathrm{t}$ ) (i.e., the thickness of the textile as the fibers were uniformly distributed) from $0.014 \mathrm{~mm}^{2} / \mathrm{mm}$ (PBO) to $0.72 \mathrm{~mm}^{2} / \mathrm{mm}$ (glass), as shown in Figure 3. Steel textiles (comprised of cords or ropes) were heavier than other textiles, the densest one having $\mathrm{i}=4.2 \mathrm{~mm}, \gamma=1,500 \mathrm{~g} / \mathrm{m}^{2}$ and $t=$ $0.188 \mathrm{~mm}^{2} / \mathrm{mm}$.

Some laboratories performed direct tensile tests on bare (i.e., not impregnated with the mortar) textile specimens, even if they were not officially foreseen in the RRT. Based on these tests and, when unavailable, on technical datasheets, the tensile strength of the fabrics $\left(\mathrm{f}_{\mathrm{f}}\right)$ used in the RRT ranges from $758 \mathrm{~N} / \mathrm{mm}^{2}$ (aramid) to $3,400 \mathrm{~N} / \mathrm{mm}^{2}$ (carbon), and the Young's modulus $\left(\mathrm{E}_{\mathrm{f}}\right)$ spans between $45.3 \mathrm{kN} / \mathrm{mm}^{2}$ (basalt) and $240 \mathrm{kN} / \mathrm{mm}^{2}$ (carbon). It should be noted that the values provided by technical datasheets are often referred to the single filament, but, due to both the spinning process to manufacture the fabric and the uneven stress state actually experienced by the wires, the tensile strength and Young's modulus derived from tensile tests on textile specimens are generally lower than those of the filament (Carozzi and Poggi, 2015).

As for the matrices, the FRCM systems comprised 17 different mortars, 9 of which were lime-based, in some cases with pozzolan (with compressive strength $\mathrm{f}_{\mathrm{c}}=6-22 \mathrm{~N} / \mathrm{mm}^{2}$ ), 6 were cementbased $\left(f_{c}=15-38 \mathrm{~N} / \mathrm{mm}^{2}\right)$, one was with lime and geopolymers $\left(\mathrm{f}_{\mathrm{c}}=20.6 \mathrm{~N} / \mathrm{mm}^{2}\right)$, and one was geopolymeric $\left(\mathrm{f}_{\mathrm{c}}=56 \mathrm{~N} / \mathrm{mm}^{2}\right)$, as listed in Table 2. Among the cement mortars, 4 were reinforced with short fibers and/or enriched with polymeric additives. Both, textile and matrix, were provided by the same supplier. Stronger and stiffer textiles (PBO, carbon) were generally combined with cement mortars, whereas weaker and more deformable fabrics (glass, basalt) were applied with lime mortars. Nevertheless, a general rule cannot be identified. Steel textiles were combined with either lime, cement, or geopolymer matrices. Finally, the aramid textiles were combined with a lime-based mortar. 
TABLE 2 | Properties of the fabrics and matrices of the FRCM composites investigated in the RRT.

\begin{tabular}{|c|c|c|c|c|c|c|c|c|c|}
\hline \multirow{2}{*}{$\begin{array}{l}\text { Textile } \\
\text { material }\end{array}$} & \multirow[t]{2}{*}{ System } & \multicolumn{6}{|c|}{ Textile properties } & \multicolumn{2}{|c|}{ Matrix properties } \\
\hline & & $\gamma\left[\mathrm{g} / \mathrm{m}^{2}\right]$ & $t\left[\mathrm{~mm}^{2} / \mathrm{mm}\right]$ & $\mathrm{i}[\mathrm{mm}]$ & Notes & $f_{f}^{(b)}\left[N / m^{2}\right]$ & $\begin{array}{c}E_{f}^{(b)} \\
{\left[k N / m^{2}\right]}\end{array}$ & Type & $\mathrm{f}_{\mathrm{c}}^{(\mathrm{b})}\left[\mathrm{N} / \mathrm{mm}^{2}\right]$ \\
\hline Aramid & $\mathrm{A} 1$ & 51 & 0.033 & Dense & $\begin{array}{l}\text { Aramid, Dry, } \\
\text { Uniaxial }\end{array}$ & $1265_{E}$ & $137_{\mathrm{E}}$ & Lime & 10.0D \\
\hline & B2 & 250 & 0.039 & $6 \times 6$ & Coated & $940_{E}$ & $45_{E}$ & Lime & 15.0 D \\
\hline & B3 & 350 & 0.058 & $25 \times 25$ & Coated & $1225_{E}$ & $70_{E}$ & Pozzolanic lime & $15.0_{D}$ \\
\hline \multirow[t]{3}{*}{ Carbon } & $\mathrm{C} 1$ & 170 & 0.047 & $20 \times 20$ & Coated & $1876_{\mathrm{E}}$ & $219_{E}$ & Cement & $16.4_{\mathrm{E}}$ \\
\hline & $\mathrm{C} 2$ & 170 & 0.047 & $10 \times 10$ & Dry & $3400_{D}$ & $240 D$ & Lime & $6.5 \mathrm{D}$ \\
\hline & C3 & 168 & 0.047 & $10 \times 10$ & Dry & $1890_{\mathrm{E}}$ & $197 \mathrm{E}$ & $\begin{array}{l}\text { Fiber reinf., cement, } \\
\text { polymers }\end{array}$ & $20.0_{D}$ \\
\hline \multirow[t]{8}{*}{ Glass } & $G 1^{(a)}$ & 250 & 0.031 & $15 \times 18$ & Coated & $1700_{D}$ & $80_{D}$ & Lime and geopolymer & $20.6_{E}$ \\
\hline & G2 & 225 & 0.035 & $25 \times 25$ & Coated & $1275_{E}$ & $72_{E}$ & Pozzolanic lime & 15.0 D \\
\hline & G3 & 218 & 0.040 & $15 \times 15$ & Coated & $1700_{E}$ & $72_{E}$ & Lime & 10.0 D \\
\hline & G4 & 220 & 0.046 & $7.6 \times 7.6$ & Dry & $1300_{E}$ & $65_{E}$ & Pozzolanic lime & 18.0D \\
\hline & G5 & 360 & 0.047 & $17 \times 12$ & Coated & $2276_{D}$ & $80_{D}$ & Fiber reinf., hydr. binder & 22.0D \\
\hline & G6 & 200 & 0.048 & $15 \times 15$ & Dry & $1300_{E}$ & $65_{E}$ & Pozzolanic lime & 18.0D \\
\hline & G7 & 250 & 0.050 & $25 \times 25$ & Coated & $2000_{D}$ & $70_{D}$ & Pozzolanic lime & 15.0 D \\
\hline & G8 & 320 & 0.072 & $12 \times 12$ & Dry & $1400_{D}$ & $74_{D}$ & Lime & $6.5 \mathrm{D}$ \\
\hline PBO & $\mathrm{P} 1$ & 44 & 0.014 & $15 \times 15$ & PBO, Dry & $3356_{E}$ & $192 \mathrm{E}$ & $\begin{array}{l}\text { Fiber reinf., cement, } \\
\text { polymers }\end{array}$ & $36.1_{\mathrm{E}}$ \\
\hline Steel & S1 & 670 & 0.084 & 6.35 & $\begin{array}{l}\text { Galvanized } \\
\text { steel cords, } \\
\text { Unidir. }\end{array}$ & $3191_{E}$ & $186_{E}$ & Lime and geopolymer & $20.6_{E}$ \\
\hline
\end{tabular}

(a) The fabric includes aramid bundles in warp direction.

(b) Subscripts denote that the value was determined experimentally (E) or taken from the technical datasheets (D).

\section{DISCUSSION OF EXPERIMENTAL RESULTS}

\section{Results of Direct Tensile and Shear Bond Tests}

The results of the tests performed on the 23 FRCM systems considered in this paper are collected in Table 3. As for direct tensile tests, $\mathrm{f}_{\mathrm{tm}}$ and $\mathrm{f}_{\mathrm{tk}}$ are the mean and characteristic (5\% fractile) tensile strengths and $E_{1 m}$ and $E_{3 m}$ are the mean slope of stress-strain curves in the first (uncracked) and third (fully cracked) stages, respectively. As for the bond tests, $f_{b m}$ and $f_{b k}$ are the mean and characteristic peak axial stresses and FM is the failure mode according to the classification recommended by de Felice et al. (2018), and recalled in section Experimental Tests Performed. The ratio $\eta=\mathrm{f}_{\mathrm{bm}} / \mathrm{f}_{\mathrm{tm}}$ represents the amount of tensile strength that is exploited at bond failure, whereas $\mathrm{f}_{\mathrm{tk}} / \mathrm{f}_{\mathrm{tm}}$ and $f_{b k} / f_{b m}$ provide a measure of the scatter of results. Note that characteristic values are calculated according to CEN (2002), as the mean minus $\mathrm{k}_{\mathrm{n}}$ times the standard deviation, $\mathrm{k}_{\mathrm{n}}$ being a fractile coefficient that depends on the number of specimens $\left(k_{n}\right.$ $=2.33$ for 5 specimens).

Figure 4A shows the average tensile strength $\left(\mathrm{f}_{\mathrm{tm}}\right)$ and bond capacity $\left(f_{b m}\right)$. The former ranges between $325 \mathrm{~N} / \mathrm{mm}^{2}$ (G6) and $3,468 \mathrm{~N} / \mathrm{mm}^{2}(\mathrm{P} 1)$. Despite a significant variability from system to system, as a general trend, the lowest values were obtained for glass FRCM composites, whereas the highest ones for carbon and $\mathrm{PBO}$ ones and for SRGs. The bond capacity ranges between 351 $\mathrm{N} / \mathrm{mm}^{2}$ (G6) and $3023 \mathrm{~N} / \mathrm{mm}^{2}$ (S1). Also in this case, there is a large variability, but there is no direct correlation between the tests with the highest $f_{t m}$ and those with the highest $f_{b m}$, as the exploitation ratios ( $\eta$ ) range between 27\% (G5) and 96\% (G4). This indicates that the bond capacity is not directly related to the 


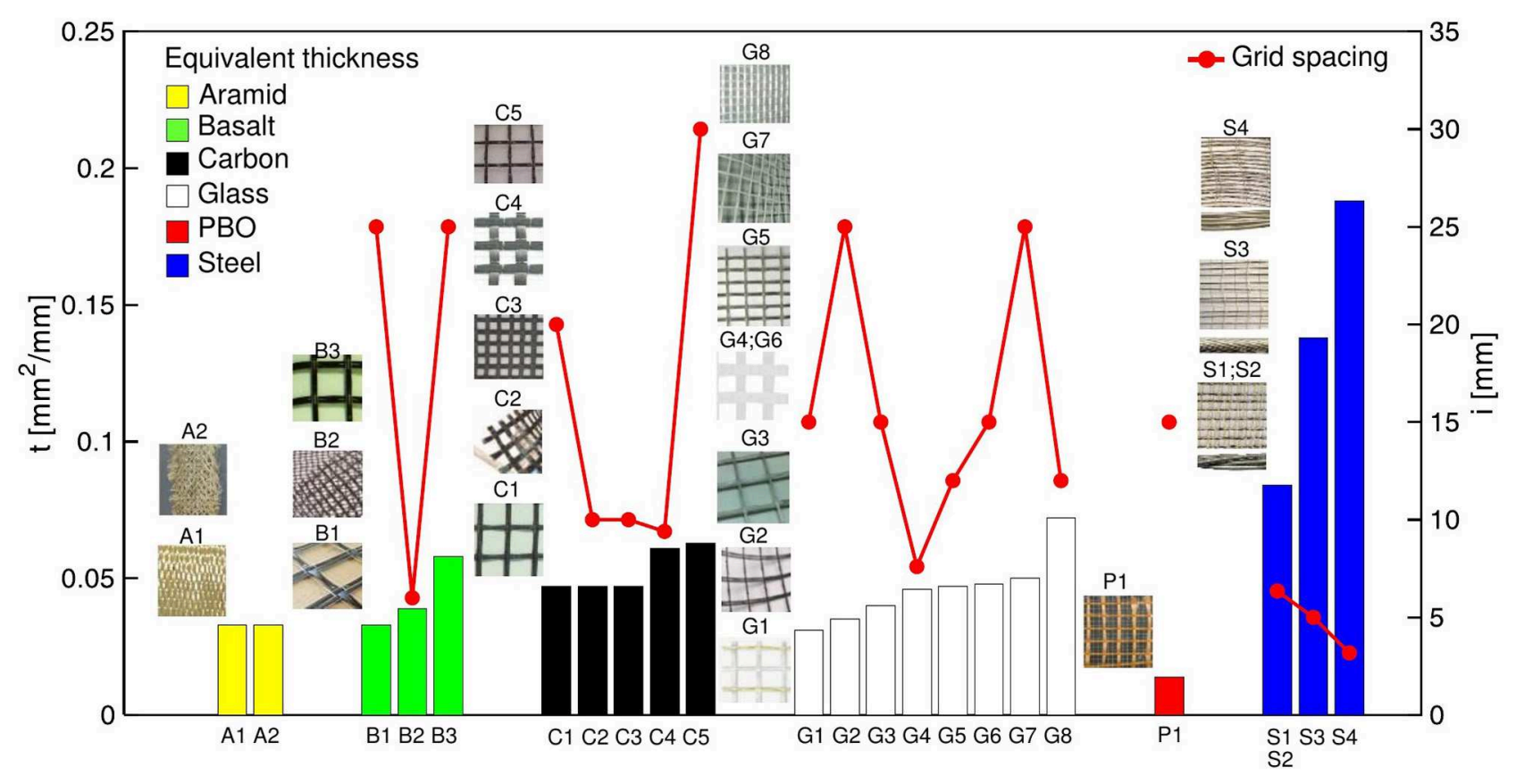

FIGURE 3 | Equivalent thickness and grid spacing of the textiles used in the RRT.

textile tensile strength or stiffness, but depends on the interaction between textile and matrix as well as to that between composite system and substrate. The different failure modes observed in the bond tests, as reported in Table 3, demonstrate that the weakest element controlling the bond capacity change from system to system, depending on its architecture, and material properties, and cannot be directly inferred from the tensile tests. The highest values of $\eta$ are associated with fabrics having either lower tensile strength, that exhibit tensile rupture in shear bond tests (occurring in some systems with basalt or glass fabrics), or particularly effective load transfer capacity as, for instance, in SRG composites.

\section{Strength Per Unit Width}

Considering that FRCM systems have different equivalent thickness, it is useful to compute load per unit width corresponding to tensile $\left(\mathrm{F}_{\mathrm{tm}}\right)$ and bond $\left(\mathrm{F}_{\mathrm{bm}}\right)$ failure, in place of stresses. Indeed, this is a useful information from an engineering standpoint to select the reinforcement, given its width, for a specific retrofitting application. Note that the type of failure depends on whether the structural application is or not bond critical, i.e., if failure will occur due to debonding of the composite or to textile tensile rupture. FRCM strips applied to a beam or a wall without connectors are expected to fail by detachment from the substrate, so their bond capacity $\left(\mathrm{F}_{\mathrm{bm}}\right)$ rules their effectiveness. Conversely, if pins or anchors are installed, or in the case of confinement (fully wrapped textile), failure generally occurs due to fiber tensile rupture, so the tensile strength $\left(\mathrm{F}_{\mathrm{tm}}\right)$ can be attained.
Figure 4B shows $\mathrm{F}_{\mathrm{tm}}$ and $\mathrm{F}_{\mathrm{bm}}$ for the 23 FRCM systems tested in the RRT. As for the stresses, the variability amongst the systems investigated leads to a wide range of strength values, $\mathrm{F}_{\mathrm{tm}}$ varying between $16 \mathrm{kN} / \mathrm{m}$ for $\mathrm{G} 6$ and $460 \mathrm{kN} / \mathrm{m}$ for S4 and $\mathrm{F}_{\mathrm{bm}}$ between $13 \mathrm{kN} / \mathrm{m}$ for $\mathrm{A} 1$ and $254 \mathrm{kN} / \mathrm{m}$ for S1. The comparison between Figures $4 \mathrm{~A}, \mathrm{~B}$ confirms that there is no direct correlation between maximum stresses and loads, highlighting the role played by the textile equivalent thickness t. For instance, the PBO FRCM (P1) has the highest tensile strength $\left(\mathrm{f}_{\mathrm{tm}}\right)$ and a bond capacity $\left(\mathrm{f}_{\mathrm{tm}}\right)$ similar to that of carbon FRCMs; nevertheless, the small design thickness $\left(t=0.014 \mathrm{~mm}^{2} / \mathrm{mm}\right)$ leads to relatively low loads per unit width, and both $\mathrm{F}_{\mathrm{tm}}$ and $\mathrm{F}_{\mathrm{bm}}$ are comparable to those of glass FRCMs.

The maximum stresses (both $f_{t m}$ and $f_{b m}$ ) of $S 4$, on the contrary, are lower than those of S1 and S2; however, thanks to its high thickness $\left(t=0.188 \mathrm{~mm}^{2} / \mathrm{mm}\right)$, the maximum load per unit width associated to detachment $\left(\mathrm{F}_{\mathrm{bm}}\right)$ is comparable to that of S1 and S2 and higher than that of all the other FRCM systems, whereas $\mathrm{F}_{\mathrm{tm}}$ is absolutely the highest one, and about $50 \%$ higher than that of the other SRGs.

An increase in the load capacity $F_{b m}$ for increasing equivalent thickness is registered for composites with basalt and glass textiles, since failure is mainly driven by the tensile rupture. Conversely, in systems with carbon fibers, the bond capacity mainly relies on the architecture of the fabric, its impregnation to avoid sliding between filaments and its coating to improve the adhesion with the matrix. It is worth noting that the maximum load per unit width is not the only parameter that orients the design of a strengthening intervention. The textile layout (unidirectional, bidirectional, or multidirectional), the stiffness 
TABLE 3 | Results of tests on FRCM composites.

\begin{tabular}{|c|c|c|c|c|c|c|c|c|c|c|}
\hline \multirow[t]{3}{*}{ System } & \multicolumn{5}{|c|}{ Direct tensile tests } & \multicolumn{4}{|c|}{ Shear bond tests } & \multirow{3}{*}{$\begin{array}{c}\text { Expl. ratio } \\
\qquad \begin{array}{c}\eta \\
\%\end{array}\end{array}$} \\
\hline & $\mathbf{f}_{\mathrm{tm}}$ & $\mathbf{f}_{\mathrm{tk}}$ & $\mathbf{f}_{\mathrm{tk}} / \mathbf{f}_{\mathrm{tm}}$ & $E_{1 m}$ & $E_{3 m}$ & $f_{b m}$ & $f_{b k}$ & $\mathbf{f}_{\mathrm{bk}} / \mathbf{f}_{\mathrm{bm}}$ & FM & \\
\hline & $\mathrm{N} / \mathrm{mm}^{2}$ & $\mathrm{~N} / \mathrm{mm}^{2}$ & $\%$ & $\mathrm{kN} / \mathrm{mm}^{2}$ & $\mathrm{kN} / \mathrm{mm}^{2}$ & $\mathrm{~N} / \mathrm{mm}^{2}$ & $\mathrm{~N} / \mathrm{mm}^{2}$ & $\%$ & & \\
\hline A1 & 1,089 & 835 & 77 & 108 & 61 & 394 & 329 & 84 & C & 36 \\
\hline $\mathrm{A} 2$ & 1,354 & 1,007 & 74 & 1,446 & 52 & 512 & 321 & 63 & $E$ & 38 \\
\hline B1 & 1,772 & 1,305 & 74 & 1,336 & 66 & 1,583 & 823 & 52 & $\mathrm{C}$ & 89 \\
\hline B2 & 1,233 & 1,018 & 83 & 768 & 48 & 1,106 & 804 & 73 & $A-C$ & 90 \\
\hline B3 & 1,985 & 1,430 & 72 & 1,599 & 74 & 1,117 & 927 & 83 & $A-C$ & 56 \\
\hline C1 & 2,832 & 2,515 & 89 & 3,426 & 196 & 1,330 & 704 & 53 & $\mathrm{D}$ & 47 \\
\hline C2 & 2,617 & 2,068 & 79 & 440 & 190 & 1,259 & 846 & 67 & C-A & 48 \\
\hline C3 & 2,587 & 2,232 & 86 & 1,782 & 154 & 1,360 & 1,141 & 84 & E-D & 53 \\
\hline $\mathrm{C} 4$ & 1,592 & 813 & 51 & - & - & 753 & 644 & 86 & D & 47 \\
\hline C5 & 1,043 & 995 & 95 & 131 & 245 & 544 & 158 & 29 & B-D & 52 \\
\hline G1 & 2,163 & 1,961 & 91 & 1,480 & 119 & 1,098 & 893 & 81 & $E$ & 51 \\
\hline G2 & 807 & 751 & 93 & 2,751 & 51 & 456 & 158 & 35 & D-E & 57 \\
\hline G3 & 611 & 312 & 51 & 1,111 & 79 & 316 & 213 & 67 & D & 52 \\
\hline G4 & 438 & 275 & 63 & 1,226 & 36 & 420 & 263 & 63 & $E$ & 96 \\
\hline G5 & 1,535 & 1,142 & 74 & - & 92 & 420 & 195 & 46 & C & 27 \\
\hline G6 & $325^{a}$ & 264 & 81 & 85 & 66 & 351 & 236 & 67 & $D$ & $108^{(a)}$ \\
\hline $\mathrm{G} 7$ & 1,242 & 1,097 & 88 & 1,592 & 52 & 644 & 569 & 88 & $E$ & 52 \\
\hline G8 & 1,294 & 1,203 & 93 & 283 & 64 & 731 & 441 & 60 & $E$ & 56 \\
\hline P1 & 3,468 & 2,175 & 63 & 10,828 & - & 1,592 & 961 & 60 & $E$ & 46 \\
\hline S1 & 3,461 & 3,252 & 94 & 914 & 184 & 3,023 & 2,961 & 98 & $\mathrm{E}-\mathrm{C}$ & 87 \\
\hline S2 & 3,365 & 2,981 & 89 & 1,718 & 186 & 2,457 & 1,672 & 68 & $B-A$ & 73 \\
\hline S3 & 1,045 & 862 & 82 & 892 & 102 & 939 & 661 & 70 & D & 90 \\
\hline S4 & 2,448 & 2,254 & 92 & 547 & 22 & 1,169 & 924 & 79 & D & 48 \\
\hline
\end{tabular}

(a) This value of $\eta>100 \%$ should be attributed to the unavoidable scatter of experimental data and interpreted as $\sim 100 \%$.

of the FRCM layer, the compatibility with the substrate and the cost, also play a crucial role. For instance, when the FRCM strip is mainly loaded in one direction (e.g., in flexural reinforcement of reinforced concrete beams or in confinement applications), unidirectional systems, such as SRG, exhibiting high loads per unit width may be appropriate. On the other hand, when FRCM strengthening is aimed to prevent cracking that may occur in multiple directions (e.g., in retrofitting of masonry walls or vaults), multidirectional textiles seem preferable. In addition, for application to existing masonry members, the stiffness of the reinforcement overlay should be carefully accounted for, to avoid excessive stiffness increments that could affect the overall behavior of the strengthened structure. Finally, although limebased matrices typically provide lower mechanical properties, they are suitable for applications on historical masonry due to their compatibility with substrate and plaster finishing.

\section{Remarks on Strength and Stiffness}

The FRCM systems are gathered according to their tensile and bond capacity vs. fabric tensile modulus of elasticity in Figures $\mathbf{5 A , B}$, respectively. In both cases, three main groups can be identified. The first one includes aramid, basalt and glass systems, which exhibit relatively low strength $\left(\mathrm{f}_{\mathrm{tm}}=\right.$ $325-2163 \mathrm{~N} / \mathrm{mm}^{2} ; \mathrm{f}_{\mathrm{bm}}=351-1,583 \mathrm{~N} / \mathrm{mm}^{2}$ ) and low fiber elastic modulus $\left(\mathrm{E}_{\mathrm{f}}=45-137 \mathrm{kN} / \mathrm{mm}^{2}\right)$. The second group includes steel and PBO systems, which have high strength $\left(\mathrm{f}_{\mathrm{tm}}=\right.$ $1,045-3,468 \mathrm{~N} / \mathrm{mm}^{2} ; \mathrm{f}_{\mathrm{bm}}=939-3,023 \mathrm{~N} / \mathrm{mm}^{2}$ ) and intermediate tensile modulus $\left(\mathrm{E}_{\mathrm{f}}=129-192 \mathrm{kN} / \mathrm{mm}^{2}\right)$. Finally, the third group include carbon FRCMs, which have a relative high tensile strength $\left(\mathrm{f}_{\mathrm{tm}}=1,043-2,832 \mathrm{~N} / \mathrm{mm}^{2}\right)$, a bond capacity comparable to glass and basalt $\left(\mathrm{f}_{\mathrm{bm}}=544-1,360 \mathrm{~N} / \mathrm{mm}^{2}\right)$ and the highest fiber elastic modulus $\left(\mathrm{E}_{\mathrm{f}}=197-240 \mathrm{kN} / \mathrm{mm}^{2}\right)$. These results can be employed to select the type of FRCM system for each specific application. Namely, systems in the first group may be considered suitable for applications where large surfaces of masonry walls or vaults need to be strengthened. Due to the limited tensile strength of masonry, important strength increases can be achieved even with FRCM systems with relatively low strength per unit width. On the other hand, when the improvement of the load bearing capacity of reinforced concrete or masonry structural members need to be achieved, FRCM systems with high stiffness and strength per unit width (those in the second and third groups of Figures 5A,B) should be considered.

\section{Comparison Between Carbon FRCM and FRP Systems}

Composite reinforcement systems comprising carbon fabrics and either inorganic (FRCM) or polymeric (FRP) binders, are compared in Figure 6, in terms of tensile strength vs. modulus 

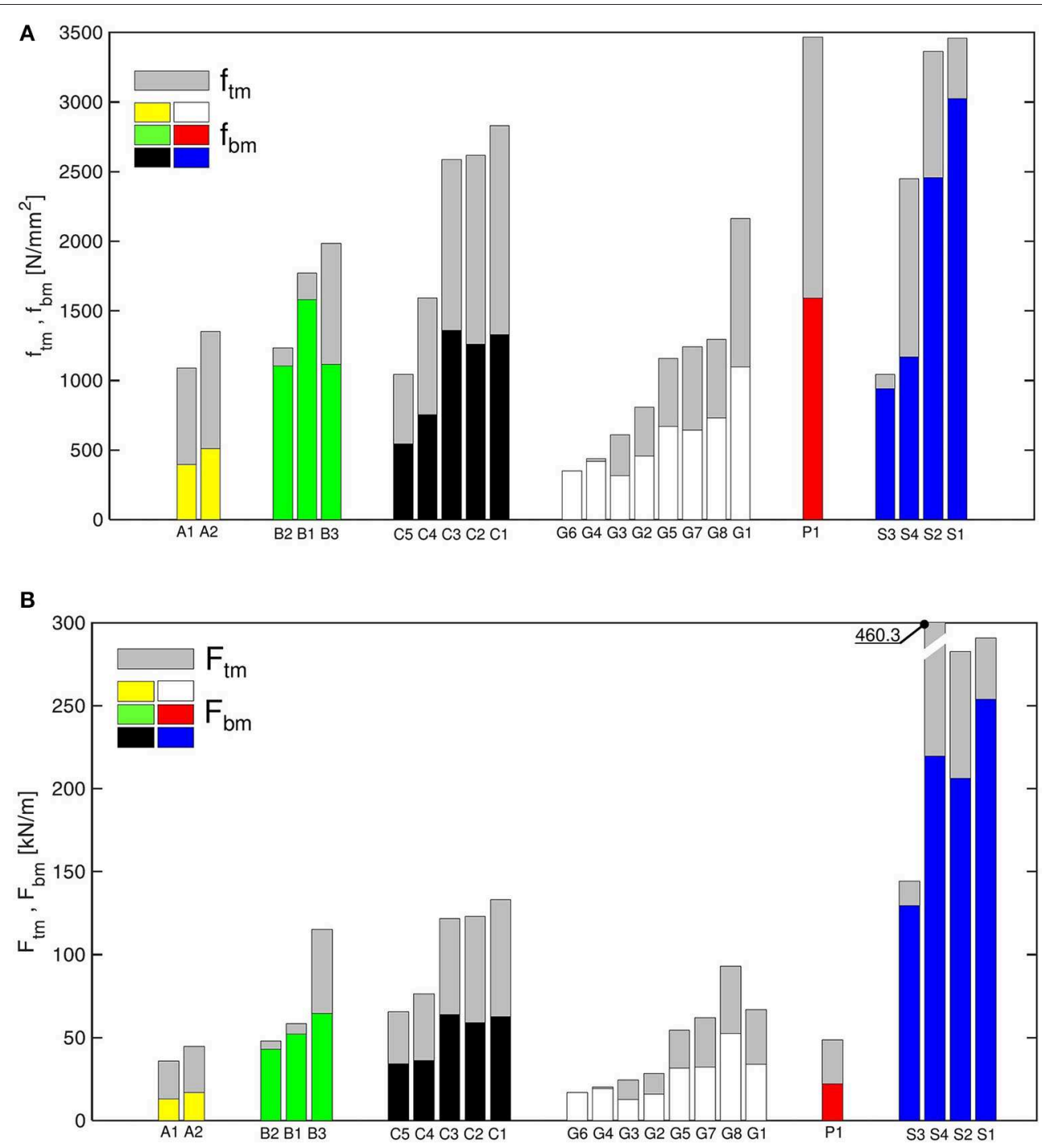

FIGURE 4 | Average maximum axial stress (A) and load per unit width (B) attained in direct tensile tests and in shear bond tests.

of elasticity. The acceptance parameters required by certification guidelines are considered for this comparison. More specifically, data on FRPs were obtained from the qualification procedure performed in Italy and include all the CFRP systems (with various surface mass density and textile Young's modulus) which have been officially certified by the Italian High Council of Public Works for use in the retrofitting of civil structures and infrastructures. The characteristic value of the tensile strength and the tensile modulus of elasticity are both obtained from direct tensile tests on FRP specimens. For FRCM systems, the acceptance parameters are the characteristic tensile strength and modulus of elasticity of the bare fabric and the bond capacity with respect to standard substrates, namely, concrete blocks and masonry prisms made by clay bricks, tuff blocks, or stone units). For FRCM composites, stresses are always referred to the cross-sectional area of the textile.
All the FRCM composites under consideration provided lower tensile strength values than FRP composites. This difference is due to the presence of organic resin in FRP composites that is able to fully impregnate the fibers providing an even stress distribution among the filaments, which in turn allows for obtaining sudden failure of the entire strip at high stress levels. In fact, the inorganic matrix employed in FRCM composites is not able to penetrate within the yarns, which results in the impregnation only of filaments located on the external surface of the yarn (sleeve filaments), whereas the inner filaments (core filaments) remain bare. This incomplete impregnation leads to an uneven distribution of the stresses within single yarns and among yarns of the textile, which in turn is responsible for subsequent rupture of single fibers (sleeve filaments first) at tensile stresses lower than those obtained by FRP composites with the same fibers. This progressive 


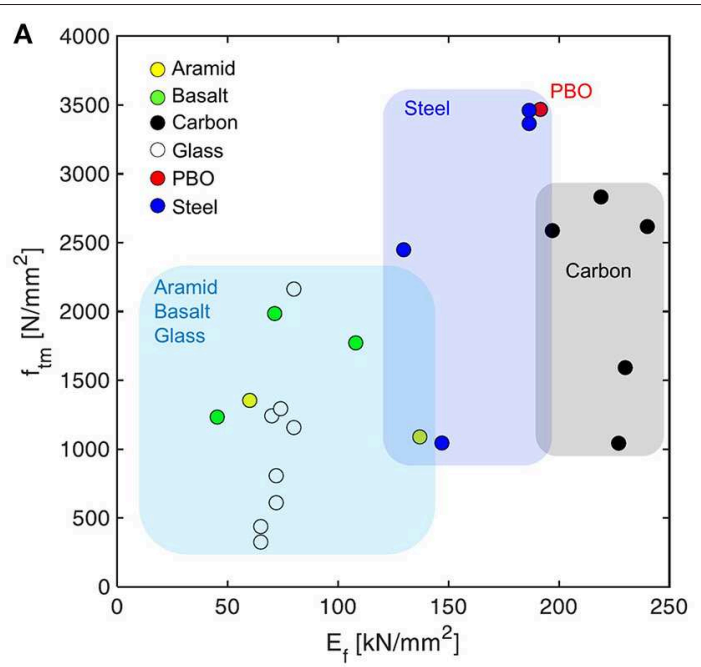

B

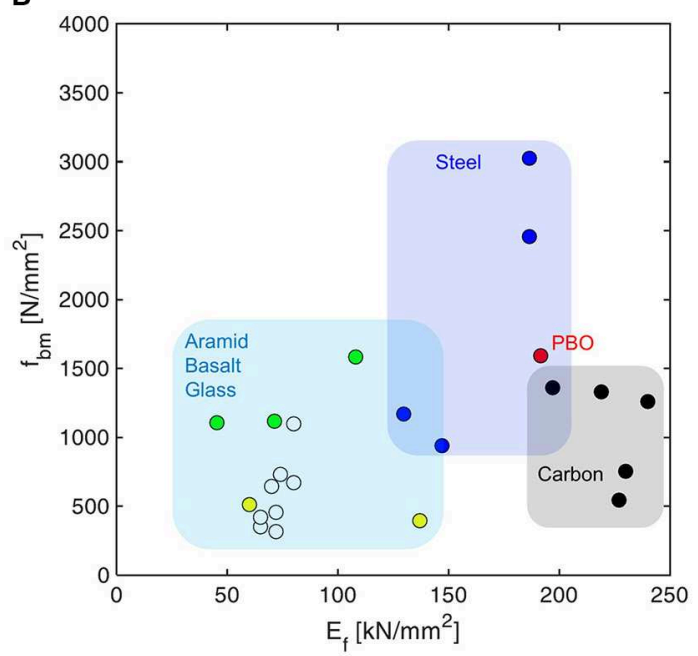

FIGURE $\mathbf{5}$ | Tensile strength (A) and bond capacity (B) vs. tensile modulus of elasticity.

failure of the filaments is also known as yarn telescopic failure (Banholzer, 2004).

The carbon FRCM bond capacities $f_{b k}$ reported in Figure 6 are generally lower than the corresponding tensile strengths $f_{t k}$, since FRCM debonding occurred before the fiber tensile strength could be fully exploited. Similarly, in carbon FRP systems, the tensile strength could not be fully exploited in absence of proper anchors, and externally bonded CFRP composites usually fail by debonding from the substrate. However, the tensile strength of organic resins employed in FRP is higher than that of concrete and masonry substrates, which determines the occurrence of cohesive debonding within the substrate.

These observations point out that carbon FRP and FRCM have peculiar characteristics that should be carefully taken into account to properly design a strengthening intervention. In general, FRP composites are more suitable for strengthening reinforced concrete structures due to their potential higher strength contribution to the member capacity, whereas FRCM

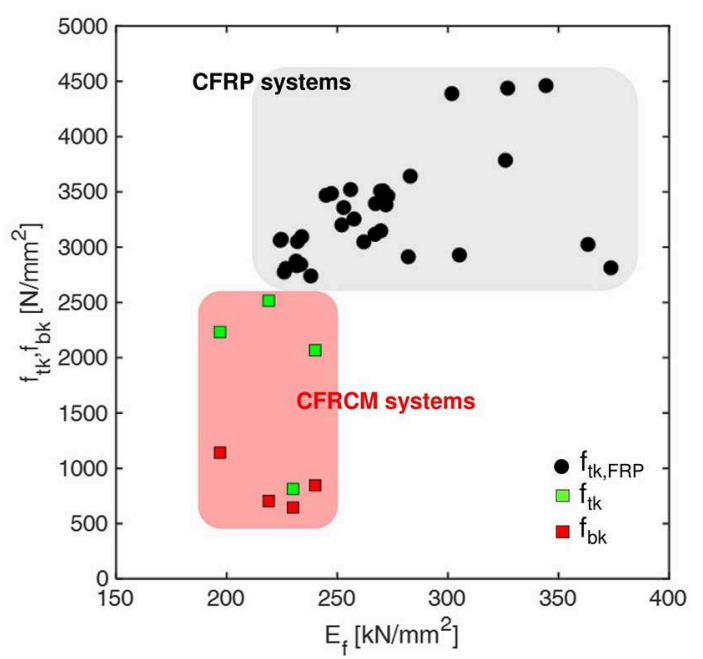

FIGURE 6 | Tensile strength vs. tensile modulus of elasticity of carbon FRCM and carbon FRP systems.

composites are more appropriate for applications to masonry members due to their good compatibility with the substrates.

\section{VARIABILITY OF TEST RESULTS}

\section{Inherent Scatter of Test Outcomes for Nominally Identical Specimens}

The ratios between characteristic (5\% fractile) and average values of tensile strength and bond capacity are shown in Figures 7A,B, respectively, to provide a measure of the scatter of experimental results. Clearly, other measures of scatter can be taken, such as the standard deviation or the coefficient of variation $(\mathrm{CoV}$, note that both are directly related to the mean/characteristic value, $\mathrm{k}_{\mathrm{n}}$ known). The $5 \%$ fractile was selected in this paper because it is the nominal strength assumed by acceptance criteria and building codes, to which tuning coefficients and safety factors apply. Since the results refer to tests performed in one laboratory on five nominally identical specimens, such scatter is associated with the inherent variability of FRCM systems. The use of inorganic matrices, which have a quasi-brittle behavior, makes FRCM composites sensitive to manufacturing, curing, and handling. Different curing procedures affect the matrix tensile strength, which is in turn responsible for the extent of the uncracked stage in direct tensile tests. Furthermore, the hydration of the inorganic matrix plays an important role in defining the matrix-fiber bond properties, which affect the results of bond tests. Finally, proper alignment of the textile with the applied load prevents the occurrence of in-plane and out-of-plane rotations of the strip, which also influence the results. All these variables may cause a certain scatter and, consequently, led to the observed difference between mean and characteristics values of tensile and bond strength. Given the large number of tests and institutions involved in the RRT, the variability observed in the tests carried out in the same laboratory might be considered as representative of the 


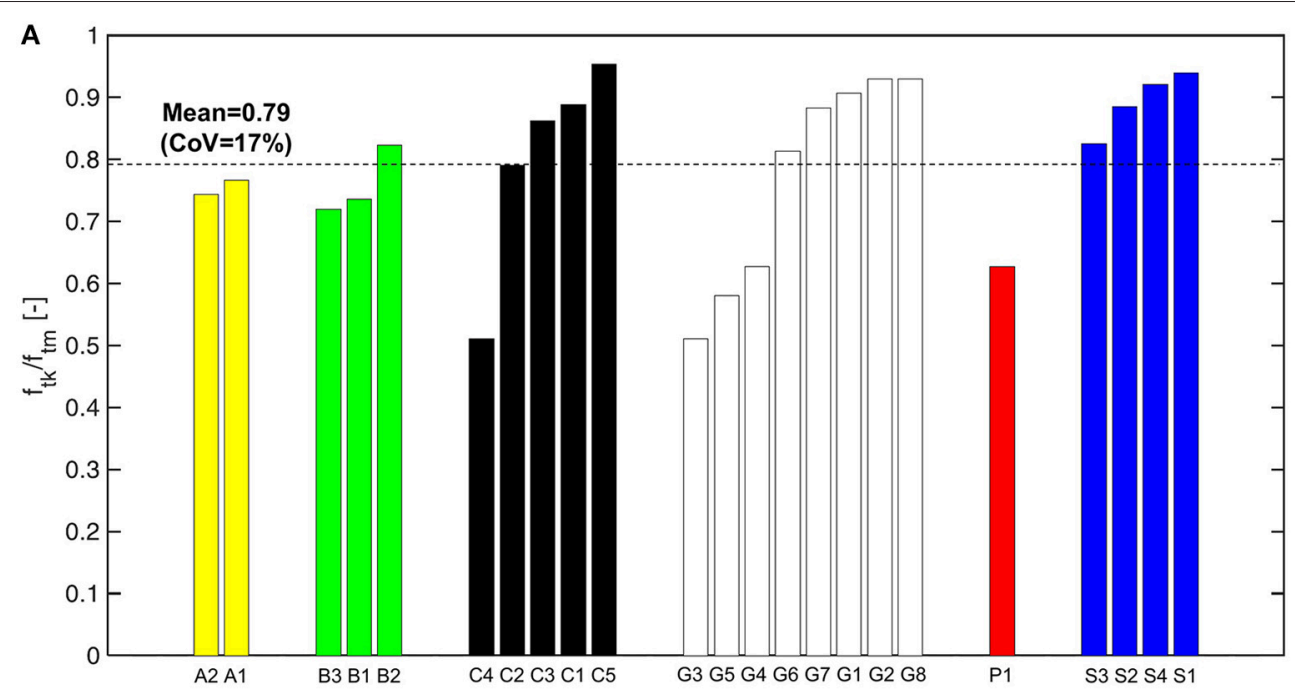

B

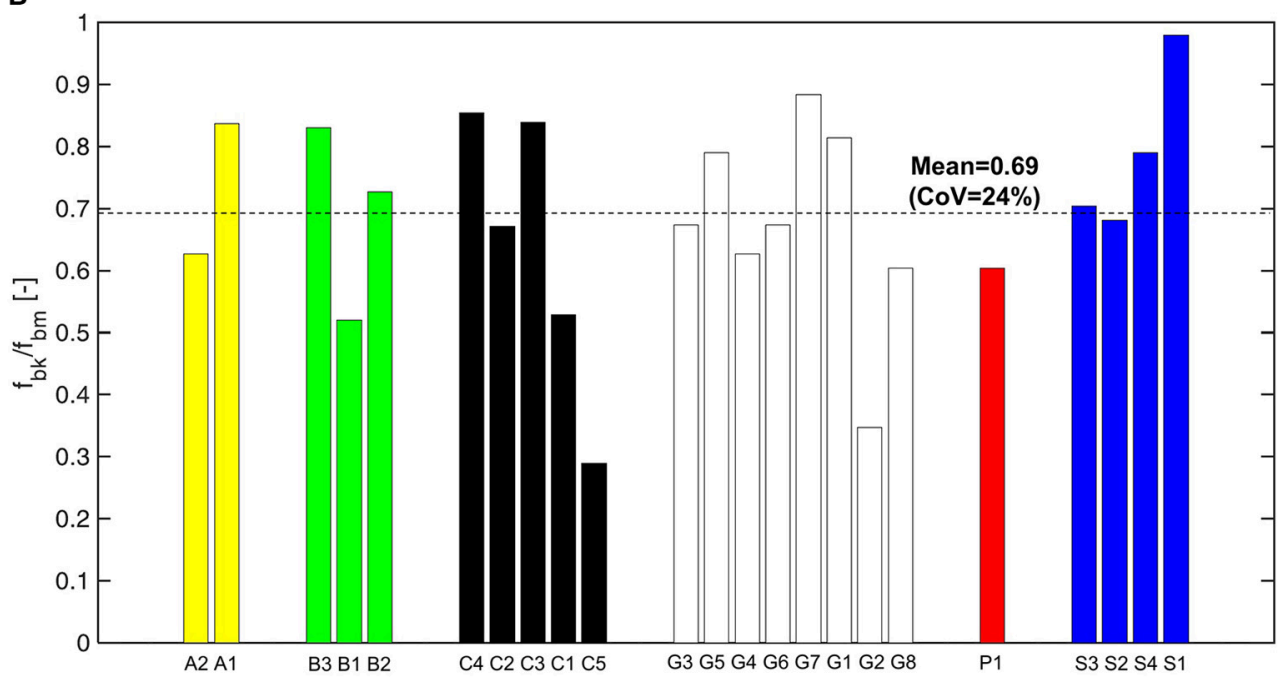

FIGURE 7 | Ratio between average and characteristic values of tensile strength (A) and bond capacity (B).

material characteristics variability. Conversely, the differences among test outcomes provided by different laboratories depend on laboratory equipment and test setup as discussed in the following section.

As for the tensile strength (Figure 7A), the characteristic value is, on average, $79 \%$ of the mean identified by the dotted line $(\mathrm{CoV}=17 \%)$. Except for SRGs, which are all above the average $\left(\mathrm{f}_{\mathrm{tk}} / \mathrm{f}_{\mathrm{tm}}=82-94 \%\right)$, and the only PBO FRCM (below the line), no clear effects associated with the fabric material are identified. Aramid and basalt systems are close to the mean, whereas glass and carbon FRCMs exhibit $\mathrm{f}_{\text {tk }} / \mathrm{f}_{\text {tm }}$ ratios between 51 (C4 and G3) and 93\% (G8). The result of bond tests are generally more scattered, $\mathrm{f}_{\mathrm{bk}} / \mathrm{f}_{\mathrm{bm}}$ being, on average, $69 \%(\mathrm{CoV}=24 \%)$ and spanning between 29 (C5) and 98\% (S1). Also in this case, SRG systems are less variable than other composites.

\section{Effects of Test Implementation and Laboratory Equipment}

The RRT showed that the results of direct tensile and shear bond tests are sensitive to implementation, which changed from laboratory to laboratory. As for tensile tests, the FRCM coupons were manufactured either individually or by cutting wider FRCM plates, using either steel, Plexiglas, or wooden molds for casting. Some specimens were cured in water, others in dedicated rooms under controlled temperature and humidity, and others in laboratory environment. Manufacturing and curing affected cracking, influencing the stiffness of the uncracked specimen and the stress and strain corresponding to the occurrence of the first crack (transition between stages I and II). The ends of the coupons were reinforced to prevent mortar crushing and spalling, as foreseen by the instructions 
shared before the RRT, but some laboratories wrapped the specimens with FRPs whereas others glued metallic or FRP tabs. The clamping methods included hydraulic or mechanical gripping by the wedges of the testing machine and bolted steel plates, which applied different pressures in the load introduction areas. Wrapping and gripping highly affected the failure mode and the maximum stress, as the occurrence of slippage in the clamping areas led to underestimate the tensile strength of the FRCM system (D'Antino and Papanicolaou, 2017; De Santis et al., 2017a). Finally, displacements and strains were measured by linear potentiometers, LVDTs, extensometers or optical methods (e.g., DIC) on measurement bases ranging from 50 to $200 \mathrm{~mm}$. The appropriateness of such base depends on the crack spacing, as short base lengths may be unsuitable for FRCM systems exhibiting large distance between cracks (D'Antino and Papanicolaou, 2018).

As for shear bond tests, manufacturing procedures changed for the content of water in the substrate before FRCM installation and for the conditions of curing (as for the coupons), which affected the failure mode and the bond capacity (for instance, insufficient water content or inappropriate curing conditions compromised the bond between FRCM strip and substrate). All the laboratories, with one sole exception, used a single-lap setup, but adopted different methods to fix the specimen and align it to the load direction. Instead, proper alignment resulted crucial for the uniform load distribution width-wise and for the application of a pure shear force at the FRCM-to-substrate interface (de Felice et al., 2018). Figure 8 shows the tensile stress (f) vs. tensile strain $(\varepsilon)$ response curves obtained in direct tensile tests performed in different laboratories. Each curve refers to one system (one FRCM per each textile material is depicted for the sake of simplicity) tested by one laboratory (average of the five tests). The plotted curves are those considered for the statistics and the discussion in this paper (Table 1). A dot is also depicted on each curve at the maximum stress attained in shear bond tests $\left(f_{b m}\right)$.

A large variability was observed for the same FRCM system from laboratory to laboratory in terms of (i) slope of the first branch and transition point between stages I and II, (ii) slope of the third branch and peak stress, (iii) strain corresponding to the peak of the curve and post-peak behavior (Caggegi et al., 2017; Carozzi et al., 2017; De Santis et al., 2017b; Leone et al., 2017; Lignola et al., 2017).

As previously observed, the different extents of the first branch and, more in general, the global shape of the response curves (e.g., the possibility of identifying a second stage, which is very difficult in some curves) should be attributed to the variability of the matrix mechanical properties, which are affected by manufacturing and curing conditions. The scatter observed in the slopes of the third branch, where the load is mainly sustained by the embedded textile, may be attributed to misalignment of the fibers with respect to the load direction, to possible matrixfiber slippage within the clamping areas, and to the differences in the axial strain measurement methods adopted. These methods also affected the strain associated with the peak stress. Finally, differences in the post-peak behavior should be attributed to a combination of such parameters, which determined an uneven matrix-fiber debonding and consequent uneven load distribution among fiber filaments and textile yarns. Even if it is difficult to associate the differences observed in test outcomes with experimental implementation procedures, because the effects of manufacturing, curing and test implementation are combined with each other, the RRT provided important information, which

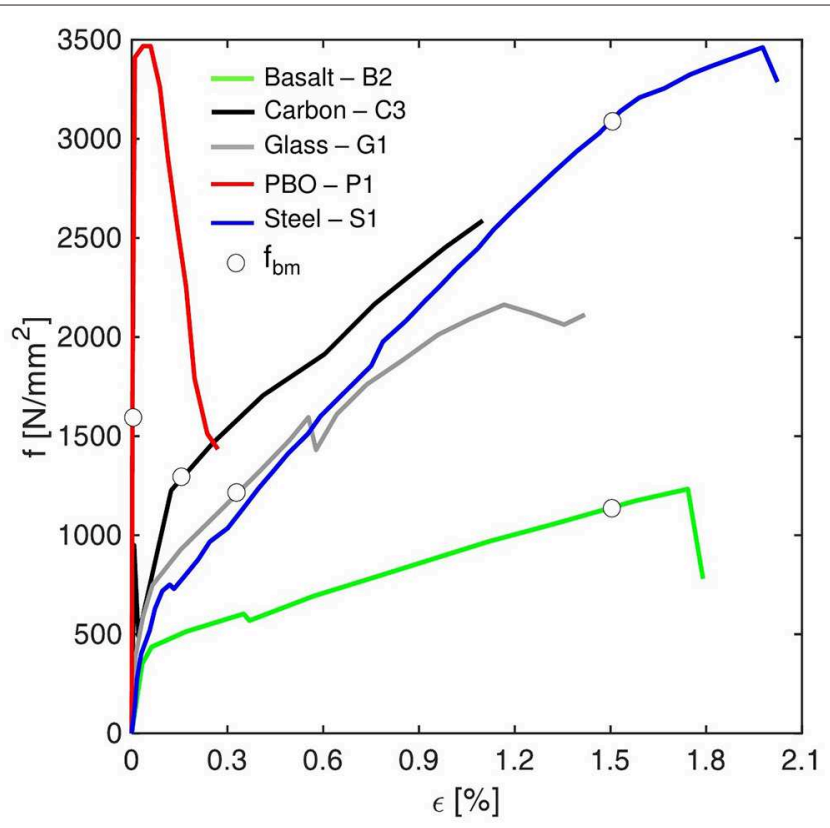

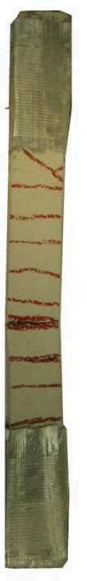

B2

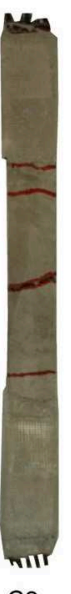

C3

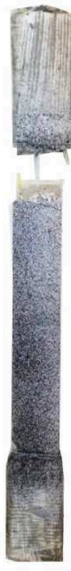

G1

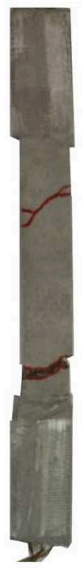

P1

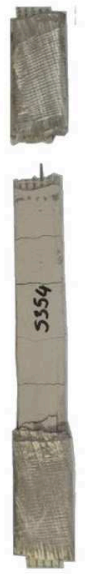

S1

FIGURE 8 | Failure modes and tensile stress vs. tensile strain response curves of basalt, carbon, glass, PBO, and steel FRCM systems. 
drove the development of testing recommendations (De Santis et al., 2017a; de Felice et al., 2018).

\section{CONCLUSIONS}

The results of a Round Robin Test performed by 19 research institutions on twenty-eight FRCM composites were collected and analyzed. The systems under investigations, which comprised basalt, carbon, glass, $\mathrm{PBO}$, aramid, and steel textiles, and lime, cement, and geopolymer mortars, reflect the variegated multitude of FRCM systems available in the market. The collection and analysis of RRT results taught important lessons on the mechanical properties of FRCM reinforcements that can be exploited in the design of a strengthening intervention, selecting the most suitable material for the specific application.

Due to the large variability of the properties of the textiles, of the mortars and of the textile-mortar interface, the mechanical characteristics of the FRCM systems tested in the RRT displayed a wide scatter. The tensile strength varied in the 325-3,468 $\mathrm{N} / \mathrm{mm}^{2}$ range, whereas the bond capacity varied between 27 to $\sim 100 \%$ of the corresponding tensile strength. Given the different equivalent thickness of the fabrics $\left(0.014-0.188 \mathrm{~mm}^{2} / \mathrm{mm}\right)$, the maximum load per unit width provided by tensile and bond tests varied between 16 and $460 \mathrm{kN} / \mathrm{m}$ and between 13 and 254 $\mathrm{kN} / \mathrm{m}$, respectively.

The scatter of the results is attributed to both the inherent variability of the response of FRCM composites and the differences in the testing procedures adopted by the involved institutions. Limited to sets of nominally identical specimens tested in the same laboratory, the $5 \%$ fractile value was, on average, $21 \%$ lower than the mean value for the tensile strength and $31 \%$ lower for the bond capacity (bond tests resulted more scattered). The differences amongst laboratories denote the sensitivity of test outcomes to manufacturing and curing conditions as well as to experimental setups (gripping methods, alignment, measurement devices, etc.). This indicates that standardized procedures able to guarantee test reliability and repeatability shall be followed, which would allow for comparing results of different materials, enhancing the confidence level on FRCM properties and enabling the control of the whole process of structural rehabilitation with FRCM, from system qualification, to retrofitting design and materials acceptance in the construction site.

The effectiveness of FRCM systems relies on the combination of textile architecture, characteristics of the matrix, and interactions between fabric a matrix and between FRCM composite and substrate. As for textile architecture, preimpregnated fabrics appear more efficient than coated and, even more, than dry textiles, as the resin impregnating the filaments provides a stress redistribution preventing premature ruptures caused by local concentrations, as well as telescopic failures associated with weak wire-to-wire bond. Although the strength per unit width grows with the design thickness, no clear correlations can be established, and such increase appears less than linear. Therefore, the amount of reinforcement embedded in the FRCM system should be carefully designed based on the specific application conditions also considering cost-efficiency. Given the same design thickness, fabrics with larger grid spacing may exhibit a higher substrate-to-FRCM bond efficiency than those with smaller spacing, thanks to the fabric-to-matrix load transfer capacity provided by the larger amount of mortar passing through the voids of the fabric.

As for the properties of the matrix, mortars with higher tensile and bond strength (cement and geopolymer mortars) may provide a higher FRCM-to-substrate bond capacity than relatively weaker ones (lime-based mortars). Lime-based matrix, however, may be more suitable for the rehabilitation of masonry due to their lower stiffness and vapor permeability. The characteristics of the matrix, mainly tensile strength and porosity, are likely to play a crucial role on long term durability (stronger and less porous mortars may provide the textile with a better protection), and this is one of the main challenges still deserving further research efforts toward a more confident use of FRCM systems for the lasting safeguarding of the built heritage.

FRCM composites are still under development. Existing systems are being improved and novel systems are continuously introduced in the market. However, the results of the Rilem TC 250-CSM Round Robin Test initiative discussed in this paper can be considered as a solid base for the thorough understanding of the main parameters governing the tensile and bond behavior of FRCM composites.

\section{DATA AVAILABILITY STATEMENT}

All datasets generated for this study are included in the article.

\section{AUTHOR CONTRIBUTIONS}

The authors made an equivalent contribution to the writing of the paper. PM and FR collected the results of the Round Robin Test and processed the data. TD'A and SD organized the Round Robin Test, worked on the interpretation of test outcomes, and wrote a first draft. GF as the chair of the Rilem TC 250-CSM, supervised the Round Robin Test and worked on the finalization of the article.

\section{FUNDING}

This work was carried out within the Research Projects SiCura, Sustainable technologies for the seismic protection of the cultural heritage (Years 2018-2020, Protocol No. 15136) and SISMI, Technologies for the improvement of the seismic safety and the restoration of historical centers (Years 2018-2019, Protocol No. 22535) funded by Regione Lazio. Funding is acknowledged also from the Italian Civil Protection Department, through the ReLUIS 2019-2021 Research Project, and the Italian Ministry of Education, University and Research (MIUR), in the frame of the Departments of Excellence Initiative 2018-2022, attributed to the Department of Engineering of Roma Tre University. 


\section{REFERENCES}

Alecci, V., Focacci, F, Rovero, L., Stipo, G., and De Stefano, M. (2016). Extrados strengthening of brick masonry arches with PBO-FRCM composites: experimental and analytical investigations. Compos. Struct. 149, 184-196. doi: 10.1016/j.compstruct.2016.04.030

Babaeidarabad, S., De Caso, F., and Nanni, A. (2014). Out-ofplane behavior of URM walls strengthened with fabric-reinforced cementitious matrix composite. J. Compos. Constr. 18:e04013057. doi: 10.1061/(ASCE)CC.1943-5614.0000457

Balsamo, A., Di Ludovico, M., Prota, A., and Manfredi, G. (2011). Masonry walls strengthened with innovative composites. Am Concr. Inst. ACI Spec. Publ. 2, 769-786.

Banholzer, B. (2004). Bond Behavior of Multi-Filament Yarn Embedded in a Cementitious Matrix, Ph.D. thesis, RETH Achen University, UK.

Bellini, A., Incerti, A., Bovo, M., and Mazzotti, C. (2018). Effectiveness of FRCM reinforcement applied to masonry walls subject to axial force and out-of-plane loads evaluated by experimental and numerical studies. Int. J. Archit. Herit. 12, 376-394. doi: 10.1080/15583058.2017.1323246

Borri, A., Casadei, P., Castori, G., and Hammond, J. (2009). Strengthening of brick masonry arches with externally bonded steel reinforced composites. J. Compos. Constr. 13, 468-475. doi: 10.1061/(ASCE)CC.1943-5614.0000030

Caggegi, C., Carozzi, F. G., De Santis, S., Fabbrocino, F., Focacci, F., Hojdys, L., et al. (2017). Experimental analysis on tensile and bond properties of $\mathrm{PBO}$ and Aramid fabric reinforced cementitious matrix for strengthening masonry structures. Compos. Part B-Eng. 127, 175-195. doi: 10.1016/j.compositesb.2017.05.048

Caggegi, C., Sciuto, D., and Cuomo, M. (2018). Experimental study on effective bond length of basalt textile reinforced mortar strengthening system: contributions of digital image correlation. Measurement 129, 119-127. doi: 10.1016/j.measurement.2018.07.003

Carloni, C., D’Antino, T., Sneed, L. H., and Pellegrino, C. (2018). Threedimensional numerical modeling of single-lap direct shear tests of FRCMconcrete joints using a cohesive damaged contact approach. J. Compos. Constr. 22:04017048. doi: 10.1061/(ASCE)CC.1943-5614.0000827

Carozzi, F. G., Bellini, A., D’Antino, T., de Felice, G., Focacci, F., Hojdys, L., et al. (2017). Experimental investigation of tensile and bond properties of Carbon-FRCM composites for strengthening masonry elements. Compos. Part B-Eng. 128, 100-119. doi: 10.1016/j.compositesb.2017. 06.018

Carozzi, F. G., and Poggi, C. (2015). Mechanical properties and debonding strength of Fabric Reinforced Cementitious Matrix (FRCM) systems for masonry strengthening. Compos. Part B-Eng. 70, 215-230. doi: 10.1016/j.compositesb.2014. 10.056

Cascardi, A., Micelli, F., and Aiello, M. A. (2018). FRCM-confined masonry columns: experimental investigation on the effect of the inorganic matrix properties. Constr. Build. Mater. 186, 811-825. doi: 10.1016/j.conbuildmat.2018.08.020

Castellano, A., Fraddosio, A., Scacco, J., Milani, G., and Piccioni, M. D. (2019). Dynamic response of FRCM reinforced masonry arches. Key Eng. Mater. 817, 285-292. doi: 10.4028/www.scientific.net/KEM.817.285

CEN (2002). European Committee for Standardization. EN 1990:2002. Eurocode 0 : Basis of structural design.

Codispoti, R., Oliveira, D. V., Olivito, R. S., Lourenço, P. B., and Fangueiro, R. (2015). Mechanical performance of natural fiber-reinforced composites for the strengthening of masonry. Compos. Part B-Eng. 77, 74-83. doi: 10.1016/j.compositesb.2015.03.021

D'Ambrisi, A., Feo, L., and Focacci, F. (2013). Experimental and analytical investigation on bond between Carbon-FRCM materials and masonry. Compos. Part B-Eng. 46, 15-20. doi: 10.1016/j.compositesb.2012.10.018

D'Ambrisi, A., and Focacci, F. (2011). Flexural strengthening of RC beams with cement-based composites. J. Compos. Constr. 15, 707-720. doi: 10.1061/(ASCE)CC.1943-5614.0000218

D’Antino, T., Carozzi, F. G., Colombi, P., and Poggi, C. (2018a). Outof-plane maximum resisting bending moment of masonry walls strengthened with FRCM composites. Compos. Struct. 202, 881-896. doi: 10.1016/j.compstruct.2018.04.054
D’Antino, T., Carozzi, F. G., and Poggi, C. (2019). Diagonal shear behavior of historic walls strengthened with composite reinforced mortar (CRM). Mater. Struct. 52:1-15. doi: 10.1617/s11527-019-1414-1

D’Antino, T., Colombi, P., Carloni, C., and Sneed, L. H. (2018b). Estimation of a matrix-fiber interface cohesive material law in FRCM-concrete joints. Compos. Struct. 193, 103-112. doi: 10.1016/j.compstruct.2018.03.005

D'Antino, T., and Papanicolaou, C. (2017). Mechanical characterization of textile reinforced inorganic-matrix composites. Compos. Part B-Eng. 127, 78-91. doi: 10.1016/j.compositesb.2017.02.034

D'Antino, T., and Papanicolaou, C. (2018). Comparison between different tensile test set-ups for the mechanical characterization of inorganic-matrix composites. Constr. Build. Mater. 171, 140-151. doi: 10.1016/j.conbuildmat.2018.03.041

de Felice, G., Aiello, M. A., Caggegi, C., Ceroni, F., De Santis, S., Garbin, E., et al. (2018). Recommendation of RILEM TC 250-CSM: Test method for Textile Reinforced Mortar to substrate bond characterization. Mater. Struct. 51:95. doi: $10.1617 / \mathrm{s} 11527-018-1216-\mathrm{x}$

de Felice, G., De Santis, S., Garmendia, L., Ghiassi, B., Larrinaga, P., Lourenço, P. B., et al. (2014). Mortar-based systems for externally bonded strengthening of masonry. Mater. Struct. 47, 2021-2037. doi: 10.1617/s11527-014-0360-1

De Santis, S. (2017). Bond behaviour of Steel Reinforced Grout for the extrados strengthening of masonry vaults. Constr. Build. Mater. 150, 367-382. doi: 10.1016/j.conbuildmat.2017.06.010

De Santis, S., Carozzi, F. G., de Felice, G., and Poggi, C. (2017a). Test methods for textile reinforced mortar systems. Compos. Part B-Eng. 127, 121-132. doi: 10.1016/j.compositesb.2017.03.016

De Santis, S., Ceroni, F., de Felice, G., Fagone, M., Ghiassi, B., Kwiecie,n, A., et al. (2017b). Round Robin Test on tensile and bond behaviour of steel reinforced grout systems. Compos. Part B-Eng. 127, 100-120. doi: 10.1016/j.compositesb.2017.03.052

De Santis, S., De Canio, G., de Felice, G., Meriggi, P., and Roselli, I. (2019a). Outof-plane seismic retrofitting of masonry walls with Textile Reinforced Mortar composites. Bull. Earthq. Eng. 17, 6265-6300 doi: 10.1007/s10518-019-00701-5

De Santis, S., Hadad, H. A., De Caso y Basalo, F. J., de Felice, G., and Nanni, A. (2018a). Acceptance criteria for tensile characterization of fabric reinforced cementitious matrix (FRCM) systems for concrete and masonry repair. $J$. Compos. Constr. 22:04018048. doi: 10.1061/(ASCE)CC.1943-5614.0000886

De Santis, S., Roscini, F., and de Felice, G. (2018b). Full-scale tests on masonry vaults strengthened with steel reinforced grout. Compos. Part B-Eng. 141, 20-36. doi: 10.1016/j.compositesb.2017.12.023

De Santis, S., Roscini, F., and de Felice, G. (2019b). Retrofitting of masonry vaults by basalt-textile reinforced mortar overlays. Int. J. Arch. Herit. 13, 1061-1077. doi: 10.1080/15583058.2019.1597947

Leone, M., Aiello, M. A., Balsamo, A., Carozzi, F. G., Ceroni, F., Corradi, M., et al. (2017). Glass fabric reinforced cementitious matrix: tensile properties and bond performance on masonry substrate. Compos. Part B-Eng. 127, 196-214. doi: 10.1016/j.compositesb.2017.06.028

Lignola, G. P., Caggegi, C., Ceroni, F., De Santis, S., Krajewski, P., Lourenço, P. B., et al. (2017). Performance assessment of basalt FRCM for retrofit applications on masonry. Compos. Part B-Eng. 128, 1-18. doi: 10.1016/j.compositesb.2017.05.003

Marcari, G., Basili, M., and Vestroni, F. (2017). Experimental investigation of tuff masonry panels reinforced with surface bonded basalt textile-reinforced mortar. Compos. Part B-Eng. 108, 131-142. doi: 10.1016/j.compositesb.2016.09.094

Napoli, A., and Realfonzo, R. (2015). Reinforced concrete beams strengthened with SRP/SRG systems: experimental investigation. Constr. Build. Mater. 93, 654-677. doi: 10.1016/j.conbuildmat.2015.06.027

Ombres, L., and Verre, S. (2019). Flexural strengthening of RC beams with steelreinforced grout: experimental and numerical investigation. J. Compos. Constr. 23:04019035. doi: 10.1061/(ASCE)CC.1943-5614.0000960

Papanicolaou, C. G., Triantafillou, T. C., Karlos, K., and Papathanasiou, M. (2007). Textile reinforced mortar (TRM) versus FRP as strengthening material of URM walls: in-plane cyclic loading. Mater. Struct. 40:1081-1097. doi: 10.1617/s11527-006-9207-8

Papanicolaou, C. G., Triantafillou, T. C., and Lekka, M. (2011). Externally bonded grids as strengthening and seismic retrofitting materials of masonry panels. Constr. Build. Mat. 25, 504-515. doi: 10.1016/j.conbuildmat.2010.07.018 
Pino, V., Akbari Hadad, H., De Caso y Basalo, F., Nanni, A., Ali Ebead, U., and El Refai, A. (2017). Performance of FRCM-strengthened RC beams subject to fatigue. J. Bridge Eng. 22:04017079. doi: 10.1061/(ASCE)BE.1943-5592.0001107

Raoof, S. M., Koutas, L. N., and Bournas, D. A. (2017). Textile-reinforced mortar (TRM) versus fibre-reinforced polymers (FRP) in flexural strengthening of RC beams. Constr. Build. Mater. 151, 279-291. doi: 10.1016/j.conbuildmat.2017.05.023

Sneed, L. H., D'Antino, T., and Carloni, C. (2014). Investigation of bond behavior of polyparaphenylene benzobisoxazole fiber-reinforced cementitious matrix composite-concrete interface. ACI Mater. J. 111, 569-580. doi: $10.14359 / 51686604$

Tekieli, M., De Santis, S., de Felice, G., Kwiecie,n, A., and Roscini, F. (2017). Application of digital image correlation to composite reinforcements testing. Compos. Struct. 160, 670-688. doi: 10.1016/j.compstruct.2016. 10.096
Valluzzi, M. R., Modena, C., and de Felice, G. (2014). Current practice and open issues in strengthening historical buildings with composites. Mater. Struct. 47, 1971-1985. doi: 10.1617/s11527-014-0359-7

Conflict of Interest: The authors declare that the research was conducted in the absence of any commercial or financial relationships that could be construed as a potential conflict of interest.

Copyright (c) 2020 de Felice, D'Antino, De Santis, Meriggi and Roscini. This is an open-access article distributed under the terms of the Creative Commons Attribution License (CC BY). The use, distribution or reproduction in other forums is permitted, provided the original author(s) and the copyright owner(s) are credited and that the original publication in this journal is cited, in accordance with accepted academic practice. No use, distribution or reproduction is permitted which does not comply with these terms. 